\title{
Los nuevos caminos del
} neoliberalismo: el caso de la economía colaborativa y el deseo de emancipación

The New Paths of Neoliberalism: The Case of the Sharing Economy and the Desire for Emancipation

Els nous camins del neoliberalisme: el cas de l'economia col·laborativa i el desig d'emancipació

Jaume Montés Mora

Universitat de Barcelona jaume.montes@ub.edu

Recibido: 19/10/2021

Aceptado: 28/12/2021 
Resumen En este ensayo se analizan los cambios sucedidos en la gubernamentalidad neoliberal y la forma en la que se han articulado un conjunto de relaciones sociales fluidas caracterizadas por la falta de orden estructural. Consecuencia de ello, han aparecido nuevos vínculos con el mercado laboral, como es el caso de diferentes apps-empresa de reparto de comida a domicilio, que implican una vulnerabilidad y precariedad que no estaban presentes en el anterior modelo fordista. Con tal de esclarecer la lógica detrás de esta economía colaborativa, el autor trata de hacer dialogar la tradición gramsciana de la hegemonía con los aportes foucaultianos del poder y así dar cuenta de algunas propuestas políticas que ayuden a pensar la construcción de sociedades del bienestar cuyo fin principal sea el tiempo garantizado.

Palabras Biopolítica, economía colaborativa, emancipación, hegemonía, neoliberalismo.

clave

\begin{abstract}
In this essay, the author analyses the changes in neoliberal governmentality and the way in which a number of social, fluid relations, characterized by the lack of structural order, are articulated. As a result, new links with the labour market have appeared, such as different food-delivery business-apps, which imply a vulnerability and precariousness that were not present in Fordism. In order to clarify the logic behind this sharing economy, the author seeks to create a dialogue between the Gramscian tradition of hegemony and Foucauldian ideas of power to account for some political proposals that may help to think about the construction of welfare societies whose main purpose is guaranteed time.
\end{abstract}

Keywords Biopolitics, Emancipation, Hegemony, Neoliberalism, Sharing Economy.

Resum En aquest assaig s'analitzen els canvis succeïts en la governamentalitat neoliberal i la forma en la qual s'han articulat un conjunt de relacions socials fluides caracteritzades per la falta d'ordre estructural. A conseqüència d'això han aparegut nous vincles amb el mercat laboral, com és el cas de diferents appsempresa de repartiment de menjar a domicili, que impliquen una vulnerabilitat i precarietat que no eren presents en l'anterior model fordista. Amb la condició d'esclarir la lògica darrere d'aquesta economia col-laborativa, l'autor tracta de fer dialogar la tradició gramsciana de l'hegemonia amb les aportacions foucaultianes del poder i així donar compte d'algunes propostes polítiques que ajudin a pensar la construcció de societats del benestar la fi principal de les quals sigui el temps garantit.

Paraules Biopolítica, economia col-laborativa, emancipació, hegemonia, neoliberalisme.

clau 


\section{Introducción}

Para todos los amantes del cine clásico, Tiempos modernos es una película de visionado obligado, ya que la obra de Charles Chaplin muestra el mejor ejemplo - tal vez un poco exagerado- del funcionamiento de la denominada sociedad fordista. Estrenada en 1936, el personaje interpretado por Chaplin está atravesado por la multitud de subjetividades contradictorias que se supone que debía experimentar la clase obrera tras el crac del 29: el hastío por el trabajo disciplinado, monótono y repetitivo de la fábrica, pero, a la vez, la depresión generada por la falta de este; el rechazo a ser un esclavo de los tiempos fabriles, pero, a la vez, la imperiosa necesidad de vender tiempo de vida para poder comer; etc. Cómicamente, el obrero encarnado por el actor estadounidense nos enseña, a lo largo de toda la película, la doble vertiente de la potencia que recorre a los trabajadores bajo el capitalismo: por un lado, la existencia de una voluntad anticapitalista de rechazo al trabajo, esto es, de rechazo a vender la fuerza de trabajo a un tercero; pero, por otro lado, el hecho de que solo a través de la venta de dicha capacidad productiva se pueden conseguir los recursos necesarios para garantizar el sustento material, es decir, la reproducción social de los propios trabajadores (Ferguson, 2020: 34-36)

Antonio Gramsci caracterizó con el nombre de "americanismo" la situación escenificada en Tiempos modernos. Según el autor, el mayor proceso de racionalización de la producción estaba teniendo lugar en los Estados Unidos de los años veinte y treinta, a través de las experiencias de Henry Ford y las teorías de la organización científica del trabajo de Frederick Taylor. Para este, el objetivo último del fenómeno norteamericano era crear un nuevo tipo de trabajador: el llamado "gorila amaestrado", un hombre-industrial que desarrollase, en su grado máximo, las actitudes maquinales y automáticas y que rompiese con el antiguo nexo psicofísico del trabajo cualificado que requería cierta participación e iniciativa del trabajador, reduciendo la producción a un simple aspecto físico y maquinal (Gramsci, 2013: 475-476).

No obstante, la tecnificación y el aumento de la productividad del capitalismo fordista tan solo eran una cara de la moneda. Gramsci consideraba que la racionalización del trabajo y las prácticas punitivas estaban íntimamente relacionadas ${ }^{1}$, puesto que uno de los problemas con los que se topaban los patronos era que no podían controlar lo que hacían sus trabajadores cuando salían de la empresa. En el período de entreguerras, con tal de evitar que los trabajadores abandonasen la

\footnotetext{
${ }^{1}$ La relación entre técnica, productividad y represión será una constante para gran parte de la teoría crítica de la sociedad desarrollada en los inmediatos años anteriores y posteriores a la Segunda Guerra Mundial. Así, Herbert Marcuse, siguiendo el camino iniciado por Gramsci, escribirá en 1953 que "la civilización tiene que defenderse a sí misma del fantasma de un mundo que puede ser libre. Si la sociedad no puede usar su creciente productividad para reducir la represión (porque tal cosa destruiría la jerarquía del statu quo), la productividad debe ser vuelta contra los individuos; llega a ser en sí misma un instrumento de control universal” (Marcuse, 2010: 90; el énfasis es del autor).
} 
fábrica y se fuesen a vivir al campo, industriales como Ford se vieron obligados a subir los salarios de sus empleados. Ahora bien, la fórmula del salario alto era de doble filo: por una parte, tenía la intención de mejorar la capacidad de cuidado, renovación y reproducción de la fuerza de trabajo; por otra, cabía la posibilidad de que muchos de estos trabajadores destinasen el aumento de sueldo a un estilo de vida (alcoholismo, prostitución, etc.) que, de hecho, perjudicase su productividad laboral. Por eso, muchos empresarios trataron de intervenir, mediante un cuerpo de inspectores privados, en la vida privada de sus empleados o promover una regulación muy estricta de las "desviaciones morales" en que pudiesen incurrir los mismos. Todo ello bajo la apariencia de una defensa a ultranza del "puritanismo" y el "humanismo. En síntesis, el autor nos advertía del peligro de que aquello que, de momento, solo era una iniciativa de algunos industriales pudiese terminar siendo asumido como una función del Estado y, por tanto, sedimentar y presentarse en la ideología dominante como un renacimiento del "verdadero norteamericanismo" (Gramsci, 2013: 475-480).

Tanto las escenificaciones de Tiempos modernos como los apuntes de Gramsci sobre el americanismo dan cuenta del doble movimiento - analíticamente distinto, pero íntimamente relacionado-que se produce en todo sistema de poder: (1) el momento hegemónico, es decir, el de esa articulación - desigual- entre coerción y consenso, entre dominación y dirección; y (2) el momento de creación de subjetividades, a saber, identidades de sujetos que moldean, disciplinan y establecen los límites de lo que puede hacer un cuerpo. Con todo, es evidente que la instauración del neoliberalismo a partir de los años setenta introdujo varios cambios sustantivos en la lógica de reproducción del capital, acrecentados aún más tras la crisis financiera de 2008. Entre ellos, cabe destacar cómo la figura del "gorila amaestrado" fue sustituida por la nueva imagen del "empresario de sí".

Por tanto, lo que sigue es un intento de analizar los nuevos vínculos con el mercado laboral, como es el caso de diferentes apps-empresa de reparto de comida a domicilio, que implican una vulnerabilidad y precariedad que no estaban tan presentes en el anterior modelo fordista. En este sentido, primero se tratará de poner en diálogo la tradición gramsciana de la hegemonía con los aportes foucaultianos del poder, con el fin de esclarecer qué cosa sea el ethos neoliberal. En segundo lugar, se desarrollará la forma de operar del neoliberalismo a partir de lo que Harvey ha caracterizado como "acumulación por desposesión" o "destrucción creativa”. Así, dichas consideraciones serán aplicadas al estudio de diferentes empresas de reparto a domicilio - tales como Deliveroo, Glovo, PedidosYa o Rappi- en tanto que representantes de la llamada economía colaborativa, la cual articula un determinado discurso en torno a la constitución de ese sujeto político que Standing (2013) denomina "precariado". Finalmente, la crítica a esta suerte de economía on demand permitirá 
proponer algunas alternativas políticas que ayuden a pensar la construcción de sociedades del bienestar cuyo fin principal sea el tiempo garantizado.

\section{Consideraciones teóricas previas: hegemonía y poder}

El concepto de hegemonía ha recibido multitud de significados a lo largo de su historia $^{2}$. Pese a que normalmente se lo suele asimilar a dominación, liderazgo o primacía, el término adquirió una nueva dimensión a partir de los escritos de Gramsci. Una interpretación rigurosa de su obra nos permite introducir una primera definición del concepto: para nosotros, hegemonía es "la construcción que permite el paso a una esfera de dirección intelectual y moral, hasta el punto de que la clase pase del particularismo al universalismo y dirija así a otros grupos sociales" (Campione, 2007: 74).

Sin embargo, pensar que existen clases sociales perfectamente constituidas en una esfera autónoma -como puede ser la económica, esto es, las posiciones que establecen las relaciones de producción de un modo de producción concreto- y sin divergencias en su seno remite a cierto marxismo ortodoxo cuyo economicismo trató siempre Gramsci de superar. Explicar los fenómenos sociales en función de quién resulta beneficiado económicamente por un acontecimiento determinado, véase una guerra, una organización estatal o una política pública, no es más que la creencia ideal en un mecanicismo estructural que debe ser rechazado (Gramsci, 2013: 400409). Por el contrario, solo puede haber período hegemónico a través de la formación de bloques históricos entre sectores sociales, diversos y contradictorios, que combinen la sección líder de la clase dirigente con la inclusión subordinada de las clases populares. Así, se logrará hegemonía cuando los objetivos particulares del grupo dirigente puedan universalizarse al conjunto de la sociedad, lo cual implica una diferencia fundamental respecto la mera dominación: también se necesita la articulación subordinada - el consenso3- de los intereses populares en el bloque

2 Dentro de la tradición socialista, Perry Anderson (1981) ya identifica el uso de este término - y de su versión anterior, gegemoniya - en los escritos de Georgi Plejánov de 1883-1884 y en los debates de la Segunda Internacional. Para una historia del concepto aún más amplia, véase el reciente Anderson (2018).

3 Por supuesto que la hegemonía no se ejerce solo a través del consenso; también hay coerción. No obstante, no se trata de una división tan evidente como la que realiza Louis Althusser (2003) entre aparato (represivo) de Estado -coerción-y aparatos ideológicos de Estado -consenso-, la cual, en última instancia, remite a la dogmática marxista clásica de que el Estado es, eminentemente, represión: una última ratio de violencia (policía, ejército, juzgados, prisiones, etc.) que se enmascara detrás de ciertas instituciones de la sociedad civil (escuela, familia, religión, etc.) que buscan el consenso de los subordinados mediante la reproducción de la ideología dominante. Es el mismo problema que tiene Anderson a la hora de entender el giro gramsciano. En realidad, la división entre sociedad política y sociedad civil no es una división entre coerción y hegemonía (consenso), sino que esta última hace referencia a la articulación, contradictoria, desigual y contingente, de sociedad política y sociedad civil 
dirigente para la constitución del régimen hegemónico (Hall, 2017: 221-223). Por eso, toda hegemonía siempre supone algo de revolución pasiva (Errejón, 2018: 2122).

Ahora bien, el bloque hegemónico, habiendo trascendido los intereses corporativo-particulares y, en consecuencia, representando el momento de "unidad nacional-popular" que hace posible la conformación de una "voluntad colectiva", no solo establece el horizonte, las aspiraciones y los deseos de la formación social; sobre todo, es capaz de definir el terreno en el que se disputará la batalla política, es decir, convertirse en "lo que se da por descontado", establecer el punto donde comienza la conversación, la escala dentro de la cual se hacen los cálculos (Hall, 2017: 223). En definitiva, establecer un nuevo "sentido común" de época. A tal efecto, ¿̇es el neoliberalismo la concreción de un régimen hegemónico - político, económico, cultural, moral e intelectual-que define las posiciones de partida de la lucha política, aquello que se considera correcto e incorrecto en el sentir popular, y, por tanto, establece los límites a cualquier alternativa contrahegemónica?

A priori, podría pensarse que sí, pues en todos los ámbitos de la vida se produce una creciente subsunción a las lógicas mercantiles que el neoliberalismo impone y normaliza, pero la discusión es mucho más compleja y no se podrá abordar en su totalidad a lo largo de estas páginas. Tan solo cabe apuntar que, si se acepta la tesis según la cual el capitalismo se reproduce circularmente de modo tal que, al no poder nombrar un exterior, se expande sin límites, desaparece la condición indispensable para el establecimiento de cualquier hegemonía: la distinción entre un "nosotros" y un "ellos" constitutivo como consecuencia de un pluralismo irreductible. Por eso, aun cuando en el neoliberalismo existe "la diferencia que llama a la diferencia" (la "vida Instagram"; el narcisismo de los selfis, tatuajes y cortes de pelo; las almas erráticas que viajan por el mundo; e, incluso, el reconocimiento de la diversidad sexual, afectiva y de género), se rechaza la diferencia que constituye a cada sujeto en algo irrepetible, incomparable y, en suma, irreductible (Alemán, 2016: 74-75). Entonces, pareciera ser que la reproducción homogeneizadora del capital se realiza en una suerte de "exclusión inclusiva"4 que es dominante, pero no hegemónica, y que deja abierta la posibilidad de construir una alternativa emancipadora.

en el denominado Estado integral (Gramsci, 2013: 291). O, en otras palabras, "al movimiento desde el polo coercitivo al polo consensual" (Hall, 2017: 224).

4 Tomamos la expresión de Giorgio Agamben (1998: 17) como una forma de caracterizar el funcionamiento del capitalismo neoliberal dominante en tanto en cuanto incluye diferentes autopercepciones (cortes de pelo, selfis, tatuajes, etc.) y distintos mandatos de consumo imperativo (competencia, el emprendedor hecho a sí mismo, endeudamiento, coaching, etc.), a la vez que excluye aquello que es fundamental para la articulación de cualquier sistema de poder hegemónico (la heterogeneidad, la diferencia, la singularidad del sujeto, la representación siempre fallida e inestable), lo cual permitiría romper con la homogeneidad imperante del orden capitalista. Evidentemente, desarrollar esa suerte de capacidad de exclusión inclusiva que tiene la nuda vida en la filosofía agambeniana -definida como un umbral de indistinción o ambigüedad entre democracia y totalitarismo por lo que respecta a la 
Hay, sin embargo, una segunda cuestión teórica que resulta imprescindible para caracterizar la gubernamentalidad neoliberal: nos referimos a los aportes foucaultianos sobre el poder. Ahora bien, una búsqueda sistemática en la obra de Michel Foucault sobre el concepto de "poder" es un ejercicio bastante fútil e infructuoso, ya que el esfuerzo conceptual del filósofo francés no estaba enfocado a establecer, definitivamente, los caracteres genéricos y diferenciales de cada término, sino que se trataba de una "conceptualización sin conceptos" (Nosetto, 2013: 197). Por ello, la base teórica que tomaremos para, posteriormente, analizar la racionalidad neoliberal se fundamentará en los cursos dictados en el Collège de France en 1977-1978 y 1978-1979, a saber, Seguridad, territorio, población (Foucault, 2008) y Nacimiento de la biopolítica (Foucault, 2009) respectivamente.

La primera clase del primero de ellos empieza con una definición inicial de biopoder, es decir:

El conjunto de mecanismos por medio de los cuales aquello que, en la especie humana, constituye sus rasgos biológicos fundamentales, podrá ser parte de una política, una estrategia política, una estrategia general de poder; en otras palabras, cómo, a partir del siglo XVIII, la sociedad, las sociedades occidentales modernas, tomaron en cuenta el hecho biológico fundamental de que el hombre constituye una especie humana (Foucault, 2008: 13).

Aquí ya podemos observar el giro que el filósofo establece respecto sus trabajos anteriores y que permite discernir una nueva modalidad, contemporánea, de los sistemas de poder. Inicialmente (siglo XII, Edad Media), encontramos un mecanismo legal o jurídico - el poder soberano- que realiza una partición binaria entre lo permitido y lo vedado, de modo que aquel que infrinja la ley recibe un tipo de castigo. A partir del siglo XVII, no obstante, aparece una segunda modulación: el mecanismo o poder disciplinario, caracterizado por todo un conjunto de "técnicas adyacentes, policiales, médicas, psicológicas, que corresponden a la vigilancia, el diagnóstico, la transformación eventual de los individuos" (Foucault, 2008: 17-18), de los cuerpos. En este período, la ley penal no solo castiga a aquel que la infrinja, sino que (1) el castigo está rodeado por toda una serie de vigilancias, controles, etc. que advierten al infractor antes de la infracción; y (2) el castigo no es solo la espada de Damocles que pende sobre nuestras cabezas y puede caer en cualquier momento (la horca, la multa o el destierro), sino prácticas como el encarcelamiento, que corrigen el comportamiento anormal de los cuerpos a través del trabajo forzado, la moralización, etc. Finalmente, es partir del siglo XVIII 5 cuando encontramos la tercera

biopolítica de individuos y poblaciones- supera con creces las pretensiones de este artículo. En este sentido, remitimos a Berrío (2010).

5 En realidad, el filósofo francés es muy ambiguo a la hora de establecer los momentos históricos en los que se producen las modulaciones entre los mecanismos de poder. En el caso del biopoder, por 
modulación, la contemporánea, que Foucault definía en el pasaje anterior: el poder biopolítico, que en este curso denominará “dispositivo de seguridad”. Ahora, el problema radica en cómo mantener, por ejemplo, un tipo de criminalidad, una enfermedad concreta, una producción determinada, etc. de una población "dentro de límites que sean social y económicamente aceptables y alrededor de una media que se considere, por decirlo de algún modo, óptima para un funcionamiento social dado" (Foucault, 2008: 17).

Las sociedades biopolíticas, que Gilles Deleuze (1990) denomina "de control”, son sociedades en las que prima la gubernamentalidad, o sea:

[...] el conjunto constituido por las instituciones, los procedimientos, análisis y reflexiones, los cálculos y las tácticas que permiten ejercer esa forma bien específica, aunque muy compleja, de poder que tiene por blanco principal la población, por forma mayor de saber la economía política y por instrumento técnico esencial los dispositivos de seguridad (Foucault, 2008: 115).

Entonces, para Foucault, el neoliberalismo es una "nueva programación de la gubernamentalidad liberal" (Brown, 2016: 156) en la que los discursos de control utilizan un lenguaje numérico y se ejercen en tanto que modulaciones, es decir, imponen, en el caso de la empresa - que reemplaza a la fábrica-, variaciones y primas para los salarios, rivalidad entre los empleados, cursos de formación permanente, etc., en oposición a la vieja sociedad fabril, analógica, que tan solo tenía un objetivo: disciplinar los cuerpos para encontrar el equilibrio entre producir el máximo al mínimo costo posible. Y esta nueva gubernamentalidad se introduce en todas las antiguas instituciones disciplinarias: penas de "sustitución" y collares electrónicos en vez de la reclusión de los presos, formas de evaluación continua y prácticas empresariales en vez de los exámenes y la investigación universitaria, medicina "sin médico ni enfermo" que trata de mantener una cifra óptima para una población determinada en vez del tratamiento individual o numérico de los cuerpos, etc. (Deleuze, 1990: 116-120).

Pese a esto, el neoliberalismo va más allá de la implantación de una nueva programación de la gubernamentalidad liberal; es también una nueva forma de racionalidad política. Si entendemos, con Foucault, que la verdad, el conocimiento y las formas de razón nunca son ajenos a las relaciones de poder, es decir, que "el poder

ejemplo, hay veces que sitúa su comienzo en la segunda mitad del siglo XVIII o principios del XIX (Foucault, 2003: 207-208), otras veces en el siglo XVII (Foucault, 2005: 168), etc. Además, cabe destacar que el autor no establece una separación tajante entre los dispositivos de poder, sino que habla de "modulaciones" que aún mantienen aspectos de los mecanismos anteriores. Lo que habría, dependiendo del período histórico, es una preeminencia de uno de los tres mecanismos de poder (el soberano, el disciplinario o el biopolítico) en relación con los otros dos (Foucault, 2008: 18-20)

${ }^{6}$ No es casualidad, pues, que Stuart Hall (2017: 225) defina la hegemonía como "liderazgo que ejerce el control, y eso es lo que significa la hegemonía: control”. 
siempre crea sujetos y órdenes que parece que solo organiza o gobierna" (Brown, 2016: 153), podremos comprender por qué no nos encontramos solamente ante una forma de ejercer el poder, esto es, ante una gubernamentalidad que se origina y emana del Estado. El neoliberalismo está constituido por discursos, por formas normativas de razón y -también- por formas de controlar, regular y conducir - ni prohibir ni prescribir, "dejar hacer" - a las poblaciones. En otras palabras, el neoliberalismo es toda una racionalidad política o rectora: un orden normativo que cambia el mundo; es hegemónico; y genera sujetos, mercados, Estados, leyes, etc. Además, es históricamente contingente, más que teleológico o necesario, pero una vez establecido gobernará y construirá un régimen de verdad hasta que otra racionalidad política lo desafíe.

Aunque las dimensiones hegemónica y biopolítica7 han sido puestas en relación en numerosos trabajos y desde distintas perspectivas (Kreps, 2015; Maltese, 2017), se puede afirmar que lo que Foucault añade a Gramsci es, por un lado, una concepción más abierta de la estructura social y, sobre todo, un entendimiento mayor de qué y cómo se constituyen las identidades, los valores y las soluciones políticos. Así, aquellos elementos gramscianos indispensables para la articulación hegemónica (coerción y consenso, sociedad política y sociedad civil, heterogeneidad irreductible, etc.) se complementan con nociones foucaultianas tales como biopolítica o gubernamentalidad, ya que estas últimas son más precisas para entender la construcción de hegemonía "en términos de ejercicio de múltiples procesos (técnicas, estrategias) de poder y sus efectos" (Olssen, 1999: 104). Por tanto, combinar ambas tradiciones conceptuales y teórico-metodológicas resulta en una concepción de las relaciones de poder más adecuada para analizar los niveles micro y macro de la formación social ${ }^{8}$.

7 Aparte de la gramsciana y la foucaultiana, habría una tercera forma analítica de abordar el neoliberalismo que puede ayudar a problematizar alguno de los aspectos enunciados más arriba, especialmente el de entender cómo el modo de producción capitalista consigue que muchos asalariados hagan causa común con el capital y marchen junto a él. Desde un punto de vista spinoziano, esta movilización es cuestión de colinealidad, esto es, de alinear el deseo de los enrolados sobre el deseo-amo. No obstante, por salirse del dualismo de raíz aristotélica que fundamenta este ensayo, dicha advertencia epistemológica no podrá desarrollarse a lo largo de estos párrafos. Para una explicación más pormenorizada, remitimos a Lordon (2015).

${ }^{8}$ Más allá de esto, poner en diálogo a Foucault con otros representantes de la tradición socialista se ha convertido en un campo de estudios realmente fructífero como consecuencia de, al menos, dos elementos. En primer lugar, la publicación póstuma de los cursos dictados en el Collège de France, en especial La sociedad punitiva (Foucault, 2018) -quizá el más "marxistizante" de todos ellos-, donde la toma en consideración de la obra de Marx y la polémica velada con Althusser y Thompson recorren buena parte del texto. En segundo lugar, la superación de la coyuntura predominante en Francia por lo que respecta a la interpretación del marxismo (Althusser, Sartre, determinados grupos maoístas), con la cual tuvo que lidiar el propio Foucault. Estos hechos han permitido realizar nuevas aproximaciones a Foucault, a Marx y a la relación entre ambos, de cuyo estudio han surgido aportaciones como la de Barrett (1991), Bidet (2014), Castro-Gómez (2005), Legrand (2004), Sardinha (2018) o la dirigida por Laval, Paltrinieri y Taylan (2015). 


\section{La acumulación por desposesión como característica distintiva del neoliberalismo}

Hasta ahora, se ha visto cómo el neoliberalismo articula, en una dirección determinada, unas demandas, deseos y aspiraciones concretas, que recuerda a aquello que advertía Gramsci cuando hablaba de la "coexistencia contradictoria de fuerzas reactivas y emancipadoras habitando en la cultura popular" (Cadahia, 2018: 11). Así pues, el análisis de la racionalidad política neoliberal debe tener en cuenta dos dimensiones clave. En primer lugar, la cuestión hegemónica, ya que el ciclo actual del capitalismo es capaz de universalizar lo particular a partir de la articulación subordinada de las aspiraciones populares. Subsume en lógicas mercantiles multitud de relaciones que anteriormente se encontraban fuera de ellas, mientras que, a la vez, es capaz de reconocer y satisfacer demandas democráticas de diferentes sectores en una suerte de revolución pasiva constante: por una parte, aísla a los individuos, mercantiliza las relaciones sexo-afectivas, produce dispositivos (wereables) que regulan las funciones vitales de las personas en su día a día, etc.; por otra, reconoce derechos LGTBI, demandas feministas, aspiraciones anticapitalistas de rechazo al trabajo, etc. En segundo lugar, la cuestión del poder biopolítico, a saber, la nueva forma que tiene el neoliberalismo de organizar los regímenes de verdad -más centrada en el “dejar hacer" y el cálculo poblacional-económico que en la disciplina de los cuerpos- y que produce subjetividades y modos en los que dichos sujetos se relacionan con su realidad material, también afectada por la nueva configuración de la gubernamentalidad liberal. A continuación, se analizará en mayor profundidad las transformaciones del neoliberalismo actual con tal de comprender la base sobre la que se sustenta la economía colaborativa.

David Harvey, geógrafo y teórico marxista británico, ha firmado estudios en los que describe la forma en la que opera el neoliberalismo en su articulación con el neoconservadurismo a principios del siglo XXI. En algunos de ellos, el autor ha tratado de examinar el estado del capitalismo actual y el papel que podría jugar lo que él denomina un "nuevo imperialismo", sobre todo en el caso de los Estados Unidos. Según Harvey (2004), la lógica capitalista del imperialismo tiende a buscar "soluciones espacio-temporales" que permitan resolver el problema del exceso de capital - una crisis de sobreacumulación, como la crisis del petróleo de 1973 o la crisis financiera-inmobiliaria de 2008-. A saber: la expansión geográfica hacia zonas que confieran una inversión rentable del capital acumulado, sumada a la inversión en infraestructuras materiales y sociales de larga duración (vías de comunicación y transporte, escuelas, hospitales, etc.).

Así pues, la argumentación principal del geógrafo inglés consiste en una reformulación de "la llamada acumulación originaria" que Karl Marx describió en el capítulo XXIV del libro primero de El capital: la acumulación por desposesión como 
mecanismo que mercantiliza cada vez más procesos y que actúa como factor primordial en el desarrollo del imperialismo capitalista. Grosso modo, dicha acumulación por desposesión libera un conjunto de activos a un precio muy bajo -o prácticamente nulo-, de forma que el capital sobreacumulado puede apoderarse de ellos y darles un uso rentable. Esto nos permite entender el cercamiento de bienes comunes que describieron Marx y E. P. Thompson o el proyecto neoliberal de privatización como formas distintas de un mismo proceso respaldado por los poderes estatales. Por tanto, si la potencia hegemónica ${ }^{9}$ es capaz de abrir nuevos mercados a la acumulación por desposesión, podrá continuar explotando una relación asimétrica que claramente le beneficia y que permitirá la reproducción de capital, es decir, que el "nuevo imperialismo" no será ni más ni menos que una reedición del antiguo, aunque en un lugar y un tiempo distintos (Harvey, 2004).

En este mismo sentido, Harvey ha reconceptualizado su concepción del neoliberalismo a partir de la famosa expresión de Joseph Schumpeter sobre la "destrucción creativa": "destrucción" en tanto que reducción de los Estados del bienestar keynesianos tras la crisis de acumulación; "creativa" en tanto que la nueva gubernamentalidad es un proyecto consistente en la restauración del poder de clase. De hecho, el autor sistematiza en varios puntos las formas que adopta esta doble vertiente del neoliberalismo, como son: (1) la privatización de activos públicos (fuerzas armadas, empresas estatales, servicios públicos, etc.) y bienes comunes (bosques, aguas territoriales, subsuelo, etc.) en una suerte de acumulación por desposesión constante; (2) la financiarización de toda la vida económica, la cual somete a los Estados al poder de la deuda; (3) la administración y la manipulación de las crisis, de tal modo que se aprovechan los momentos de excepción para transferir activos a las clases dominantes; $y$, finalmente, (4) una forma diferente de redistribuciones estatales, es decir, que una vez que el Estado se ha convertido en una maquinaria neoliberal cuyas instituciones han restaurado el poder de clase, se ponen en marcha toda una serie de mecanismos que desarticulan cualquier tipo de organización de la sociedad civil. Ejemplos de estos últimos son la privatización de las viviendas sociales durante el gobierno de Margaret Thatcher en el Reino Unido o de los ejidos en México, los cambios regresivos en el código tributario que benefician las inversiones en capital financiero en vez de las inversiones en ingresos y salarios o el aumento de la vigilancia y los aparatos represivos de Estado (como la Patriot Act en los Estados Unidos tras los atentados del 11S) (Harvey, 2008: 21-28) ${ }^{10}$.

9 Cabe destacar que, en realidad, Harvey utiliza la noción de hegemonía de una forma particular: recurriendo a Giovanni Arrighi, adapta el concepto al campo de las relaciones internacionales, de modo que esta "implica el uso del liderazgo para crear un juego de suma positiva en el que todas las partes se beneficien" (Harvey, 2004: 46).

10 Por cuestiones de espacio, no se ha desarrollado lo que generalmente se considera como el origen simbólico del neoliberalismo: el "Nixon Shock" del 15 de agosto de 1971 por el cual el gobierno estadounidense suspendió la convertibilidad directa del dólar en oro y canceló unilateralmente los 
Aun cuando el análisis de Harvey está muy centrado en la lógica territorial del capitalismo y adolece de un supuesto simplificador demasiado reduccionista -el neoliberalismo como proyecto restaurador del poder de clase- $-{ }^{11}$, creemos que la noción de acumulación por desposesión -o el aserto schumpeteriano de destrucción creativa - es la característica distintiva con la que se puede describir el modo de producción actual, sobre todo después de la crisis financiera de 2008. El neoliberalismo supone la creciente subsunción a lógicas mercantiles de la mayor parte de las relaciones sociales: sexo y afectos que siguen una dinámica de oferta y demanda en Tinder; anuncios de bancos según los cuales "enamorarse sale caro"; discurso del coaching como justificación de la precariedad laboral; aplicaciones para móviles en las que uno se ofrece para quedar a cenar como si fuese el mejor amigo de toda la vida, para dormir abrazado junto a otra persona o para ofertar los restos de comida de un restaurante; la falsa figura del "empresario de sí" que se ve obligado a capitalizar su tiempo libre con el fin de obtener ingresos extra que le permitan subsistir a lo largo de la semana; el control social que ejerce Instagram en una suerte de "panóptico integrado" (Moruno, 2018: 27); etc. En síntesis, un sistema de poder que es hegemónico en tanto en cuanto se presenta como lo ya dado, lo natural, incluso lo verdadero, sustentado en un discurso de apariencia científica y objetiva y que, a la vez, constituye una racionalidad política que impregna toda la realidad social y que genera nuevas subjetividades: discursos, formas normativas de razón y configuraciones gubernamentales.

Estas nuevas relaciones son, en consecuencia, fluidas, precarias y vulnerables (Tsing, 2021: 41-42). ¿Acaso son lo mismo las amistades en Facebook, privadas e individuales, que el contacto directo con el resto de personas en el espacio público? ¿Acaso es lo mismo el ciberactivismo que la militancia organizada? ¿Hay diferencia entre la planificación urbana actual, en la que no se construyen espacios de reunión, y la planificación urbana anterior, caracterizada por plazas y parques? ¿Cuáles son las implicaciones de las relaciones poliamorosas y de la "vida Tinder”? ¿Cómo se produce la emancipación cuando el tiempo de vida se identifica con el tiempo de trabajo y uno ya no sabe si debería contestar al correo electrónico del jefe durante el fin de semana o ponerse a pedalear una bicicleta para conseguir ingresos extras? Byung-Chul Han ha analizado estos cambios a partir de una conceptualización del

acuerdos de Bretton Woods, los cuales habían regido la política económica mundial desde 1945. Esta decisión, entre otras, motivó la aparición de esta suerte de "gubernamentalidad financiera" (Agüero, 2010) que se está analizando a lo largo del artículo y ha confirmado la tesis de Agamben (2017: 113132) que, retomando el texto homónimo de Walter Benjamin, define el capitalismo como una religión - "Dios no murió, se convirtió en dinero"-.

${ }^{11}$ En palabras de José A. Estévez Araújo (2021: 24-25), “no se pretende, con esto, 'deducir' todo lo que ha ocurrido en estas últimas décadas de la premisa de la restauración, ni considerar que las diversas transformaciones que se producen son ‘funcionales' a este propósito. Pero no resulta descabellado utilizar la lucha de clases como criterio de orientación para identificar los aspectos más importantes de los procesos que ha puesto en marcha la globalización neoliberal [...]”. 
poder que, según el propio autor, iría incluso más allá del biopoder foucaultiano: el "psicopoder". Para el filósofo surcoreano, la psicopolítica ya no se ejerce a través de un "Gran Hermano" que regula la conducta externa de las poblaciones "desde fuera”, sino que la vigilancia, el control y el "dejar hacer" se hace "desde dentro": "la psicopolítica digital se apodera de la conducta social de las masas, pues echa la zarpa en su lógica inconsciente" (Han, 2014: 81).

Así pues, si la acumulación por desposesión es el modo de actuación distintivo del neoliberalismo, la carencia de orden estructural en las relaciones sociales es su resultado definitivo. El proyecto de la racionalidad neoliberal no es otro que el de licuar la fuerza de los enrolados, someterlos a tensiones inauditas en el trasfondo del desempleo de masas y hacerlos entrar en un mundo de incertidumbre extrema (Lordon, 2015: 65-66). Y cuando todos los días los asalariados van al trabajo "muertos de miedo", cuando la gente se enfrenta a una situación de anomia radical:

La necesidad de alguna clase de orden se vuelve más importante que el orden óntico que permita superarla. El universo hobbesiano constituye la versión extrema de este vacío: como la sociedad se enfrenta a una situación de desorden total (el estado de naturaleza), cualquier cosa que haga el Leviatán es legítima - sin importar su contenido, siempre que el orden sea su resultado (Laclau, 2005: 116; el énfasis es del autor) ${ }^{12}$.

Por ello, se tratará de aplicar estas consideraciones al estudio de la denominada economía colaborativa como ilustración de los nuevos caminos que ha tomado el neoliberalismo en cuanto a las relaciones laborales. Sin embargo, antes dibujaremos, genealógicamente, algunos trazos de lo que caracteriza al capitalismo: la sociedad de trabajadores.

\section{4. "Capitalismo con tracción a sangre"}

Cabe destacar que la noción actual de trabajo es un producto de la modernidad, específicamente, de la sociedad industrial. De hecho, el trabajo manual estaba mal visto en las sociedades griegas y romanas, ya que se consideraba un obstáculo para la realización de las actividades cívicas, o sea, públicas. Durante la Edad Media, el campesino (villanus) era sinónimo de siervo (servus) y, hasta el siglo XVIII, el

\footnotetext{
12 En dicho fragmento, Ernesto Laclau se refiere a la indeterminación de la relación entre la función ontológica de la construcción discursiva y el contenido óntico de dicha articulación. Es decir, que la necesidad social de condensar en torno a sí todo un campo antagónico puede ser satisfecha por significantes de signo político completamente opuesto. De ahí la tesis laclausiana de que entre el populismo de izquierda y el populismo de derecha existe una "nebulosa tierra de nadie" que puede ser cruzada y ha sido cruzada- en muchas direcciones (Laclau, 2005: 115). Para una explicación de por qué los significantes vacíos son importantes para la política, puede consultarse el texto homónimo en Laclau (2007: 36-46). En nuestro caso, sería posible analizar el (re)surgimiento de la extrema derecha tras la crisis de financiera de 2008 como una respuesta ante esta falta de orden resultante del proyecto neoliberal.
} 
término se utilizaba primordialmente para designar a aquellos jornaleros que producían bienes de consumo. Es a partir de la entrada en la modernidad, es decir, de la irrupción de la sociedad capitalista-industrial, cuando comenzó a configurarse aquello que podemos denominar "sociedad de trabajadores": desde entonces, el trabajo ha perdido su significado original (poiesis), esto es, la capacidad de creación propia, antropológica, del ser humano, y se ha instituido como la fuente de socialización principal (Moruno, 2015: 52-55). En otras palabras, el trabajo ha pasado a ser reconocido como el origen de la identidad social: una actividad que se realiza en el espacio público y que, subsumida a las lógicas capitalistas, permite a los pocos apropiarse de la plusvalía que generan los muchos. Es así como, gradualmente, se van colocando los cimientos del edificio civilizatorio cuyo eje principal es el trabajador formalmente libre que vende su fuerza de trabajo a un capitalista poseedor de máquinas, instalaciones y dinero.

Por tanto, si en la sociedad premoderna no se distinguía entre tiempo de vida y tiempo de trabajo, pues el acceso a los medios de vida era comunal ${ }^{13}$, el capitalismo, con el fin de expandirse, necesitó apropiarse de dichos medios de vida y así obligar a los trabajadores a vender su fuerza de trabajo en un mercado laboral. De este modo, el tiempo de vida y el tiempo de trabajo aparecieron como dos esferas completamente separadas. Sin embargo, tanto la distinción entre ambas dimensiones como el proyecto de conseguir que el trabajo se convirtiese en el principal mediador social fueron dos tareas arduas y costosas. Como Thompson (1984: 239-293) ha puesto de manifiesto, los trabajadores internalizaron dicha diferenciación en tanto que dejaron de trabajar regidos por el tiempo de las temporadas, las cosechas, etc. $\mathrm{y}$ pasaron a hacerlo por los ritmos que marcaba el reloj, recientemente introducido en sus vidas. El tiempo dejó de pasar; ahora se gastaba. En consecuencia, se establecieron los horarios de entrada y salida, se delimitaron los tiempos de descanso y retraso, desapareció la discriminación entre las temporadas de producción y las de desocupación, se suprimieron algunos feriados, etc. Tras esto, la ideología en la que se basa la sociedad de trabajadores quedó instaurada hasta el día de hoy: el trabajo pasó a constituir la actividad pública principal, se convirtió en una obligación social y en sinónimo de éxito personal - mientras que aquellos que rechazaban trabajar era etiquetados como parias o lastres de la sociedad-. Incluso el movimiento obrero de los siglos XIX y, sobre todo, XX, el cual perseguía el objetivo de una sociedad emancipada, se construyó alrededor de la identidad impuesta del trabajador (Moruno, 2015: 61-63).

13 La distinción entre tiempo de vida y tiempo de trabajo tampoco operaba en las formas de trabajo no comunales, como el esclavismo o el feudalismo. En el primer caso, el esclavo no vendía su fuerza de trabajo, sino que se lo compraba como un todo, para siempre o hasta que otro esclavista volviera a comprarlo. En el segundo caso, los campesinos siervos se veían obligados a trabajar la tierra del señor feudal, en un tiempo y espacio determinados, obligatoria y gratuitamente. 
Nos encontramos, pues, ante el ejercicio del poder disciplinario al que hacíamos referencia más arriba, esto es, el conjunto de "técnicas adyacentes, policiales, médicas, psicológicas, que corresponden a la vigilancia, el diagnóstico, la transformación eventual de los individuos" (Foucault, 2008: 17-18). Escenificado en la "fábrica-fortaleza", la "fábrica-ciudad" y, en su máxima expresión, el taylorismo y el fordismo, el objetivo era crear el denominado "gorila amaestrado", a saber, un nuevo tipo de hombre que no necesitase ningún conocimiento técnico específico y en el que hubiese desaparecido la pulsión de rechazo al trabajo (Gramsci, 2013: 480-481). En este sentido, resulta curioso que actualmente haya varios autores considerados de izquierdas que promuevan la vuelta a un pasado glorioso, en el que el trabajo era la fuente de identidad principal y de generación de riqueza, sin recordar que no era tan glorioso ni homogéneo como pretenden. No entienden que capital y trabajo son dos caras de una misma moneda. Se autodenominan marxistas, pero parece que no se acuerdan de aquella frase de Marx en la Crítica del programa de Gotha en la que dice que lo que debe emanciparse no es el trabajo, sino la clase obrera del trabajo. iEntiéndalo quien pueda! (Marx y Engels, 1975, II: 18).

El odio al trabajo es, probablemente, una potencia que ha recorrido el movimiento obrero desde sus inicios y que alberga en su seno una enorme capacidad innovadora. Adam Smith (1994: 40) explicaba una anécdota que ejemplifica perfectamente la potencia del rechazo a ser una mercancía que se explota dentro del circuito de valoración capitalista. Según el economista escocés, en las primeras máquinas de vapor se empleaba a un muchacho cuya única función era abrir y cerrar la válvula de comunicación entre la caldera y el cilindro. Una vez, uno de estos muchachos averiguó que, si ataba una cuerda desde la manivela hasta otra parte de la máquina, la válvula se abría y cerraba sin su ayuda, lo cual le daba más libertad para jugar más tiempo con sus compañeros. Es la misma fuerza que recorre a Billy Elliot al preferir el ballet a trabajar en la mina como su padre o a los jóvenes que gritan en las marchas aquello de "los hijos de los obreros queremos estudiar". Tiempos modernos en estado puro.

Aun cuando la pulsión de rechazo al trabajo trató de contenerse a través de la movilización del deseo alegre que generaba la promesa del consumo ampliado durante el período fordista (Lordon, 2015: 49-50), la identificación entre el obrero y la máquina explotó a finales de la década de los sesenta. El trabajador se negaba a ser una pieza más del proceso productivo - “cuanto más produce, más se aliena”- y decidía ampliar sus horizontes culturales, sociales y sexuales más allá de lo explorado (Moruno, 2015: 69), hasta el punto de que: 
Ante el problema de los vaivenes del mercado y ante el riesgo, la inseguridad y la fragmentación del vivir, la solución ideada por el neoliberalismo para los sujetos gobernados es aprender a ser flexible, adaptarse rápidamente y convertirse en empresario de sí (Bedoya y Castrillón, 2017: 41).

¿Qué es, entonces, lo que caracteriza a la sociedad de trabajadores bajo el neoliberalismo, especialmente tras la crisis financiera de 2008? Una nueva transformación del tiempo interno, de tal modo que tiempo de trabajo y tiempo de vida han vuelto a juntarse (Moruno, 2015: 72-73). Aquella demanda que el movimiento obrero levantó a lo largo del siglo XIX y principios del XX y que reivindicaba "ocho horas para trabajar, ocho horas para dormir y ocho horas para vivir" ya no es definitoria del ciclo actual del capitalismo. Hoy en día, no sabemos cuándo trabajamos y cuándo disponemos de momentos de ocio; todo nuestro tiempo está subsumido a las lógicas neoliberales. Ya no existe un patrón que diga qué hacer cuando se está delante de la cadena de montaje; ahora, todo el mundo es jefe de sí mismo, esto es, un sentido común hegemónico que nos sobrevuela y actúa como inconsciente freudiano cuando estamos de fiesta, divirtiéndonos, viajando en el metro y -por supuesto- en nuestro lugar de trabajo. En palabras de Jorge Moruno:

Esto supone que te responsabilices autónomamente y que aumente el grado de servilismo con respecto al ritmo que impone el capitalismo. Sin antes la relación del trabajo funcionaba bajo el apotegma de Rosa Luxemburgo, quien no se mueve, no siente las cadenas, ahora quizá describen mejor la realidad posdisciplinaria las palabras de Bob Marley, cuando en la canción Concrete Jungle incide en que no hay cadenas a mi alrededor, pero no soy libre (Moruno, 2015: 74-75; el énfasis es del autor).

La denominada economía colaborativa o de plataformas constituye la máxima expresión de este camino que se viene recorriendo desde los años setenta, es decir, la (falsa) promesa de un trabajo libre, sin jefes, sin horarios y con ganancias inmediatas. Llámese Deliveroo, Glovo, PedidosYa o Rappi, la economía on demand explota, en última instancia, el deseo anticapitalista más primigenio de todos: dejar de ser trabajador. Por ponerlo en los términos del CEO de Rappi en Argentina, los que participan en la economía de plataformas no son trabajadores formales, sino "microempresarios, porque disponen de su propio tiempo" (Gullo, 2018). A continuación, nos centraremos en analizar las dimensiones hegemónica y biopolítica de estas apps-empresa, en tanto que la mayoría de ellas se caracterizan por precarizar las condiciones laborales de sus "falsos autónomos" (Chen y Sun, 2020; Drahokoupil y Piasna, 2019; Woodcock, 2020).

Los trabajadores de estas aplicaciones de reparto a domicilio no cuentan con seguro ni obra social ni vacaciones ni beneficios sindicales de ningún tipo. Al encontrarse en un limbo laboral, en el que no son ni autónomos ni trabajadores formales 
con un contrato al uso, toda la responsabilidad recae sobre ellos (Tassinari y Maccarrone, 2020: 37-38)14. Por lo general, estas empresas dan poca importancia a la seguridad vial, obligan a sus usuarios a utilizar sus propias bicicletas y alquilan a precio de oro la caja-mochila con la que los repartidores trasladan la comida. Su discurso se nutre de la precariedad, mayoritariamente juvenil-estudiantil (Drahokoupil y Piasna, 2019) e inmigrante (Chen y Sun, 2020), pero también del odio al trabajo que se comentaba más arriba: eres tu propio jefe, trabajas las horas que quieres, la ganancia -más propina- la establece un algoritmo objetivo en cada reparto, aprovechas tu tiempo libre para hacer deporte, no contaminas y te diviertes. En el imaginario colectivo: el rechazo a la disciplina del patrón, a la jornada laboral repetitiva, a la relación de dominación salarial, al "no me da la vida" y al enfurruñamiento de ir a trabajar los lunes.

$\mathrm{Y}$, sin embargo, no existe el grado de libertad que vociferan sus publicistas ${ }^{15}$. Si un rider rechaza un pedido, su cuenta es bloqueada; la empresa lo trata como un proveedor cualquiera, ya que no recibe el pago por su reparto hasta varias semanas después de realizarlo; está constantemente controlado por un GPS al cual los usuarios que han hecho el pedido tienen acceso; lo despiden desde una Tablet; etc. Pero el repartidor solo pedalea una bici. De ahí que Jamie Woodcock (2020) hable de una nueva modulación en los modos de vigilancia y castigo sociolaborales: del panóptico clásico de la fábrica y del panóptico electrónico de los call center se ha pasado al "panóptico algorítmico" de compañías como Deliveroo. Como bien dice Emiliano Gullo (2018), "los nuevos modos de explotación parecen evolucionar de una manera bastante singular: el siglo XXI a mano de las empresas, los trabajadores anclados en el siglo XIX"16.

14 De hecho, en una encuesta online realizada a 158 trabajadores londinenses de Deliveroo, un 87,1 \% de los participantes contestó que no creía que su estatus - trabajadores por cuenta propia- reflejase correctamente la naturaleza de su trabajo; un 97,8 \% demandaba un incremento de sus derechos laborales (pensiones, permisos de paternidad, vacaciones pagadas y bajas laborales); y un 95,7 \% pensaba que la compañía debería hacerse responsable de cumplir con determinadas medidas de seguridad laboral, tales como pagar una mutua o proveer formación adecuada (Woodcock, 2020: 78-79).

15 En 2018, la página web de contratación de Deliveroo - la cual ha dejado de operar en numerosos países, Alemania y España entre ellos-, ofrecía: "tú decides cuándo trabajar. Trabajar con Deliveroo te da flexibilidad e independencia. Y siendo autoempleado, disfrutas de todas las ventajas de trabajar a tu propio ritmo"; algo parecido aparecía en la web de Foodora - una empresa fundada en Alemania que ahora solo opera en Finlandia, Noruega y Suecia-: “¿Sabes por qué hay tantos 'ciclistas rosas' pedaleando por Berlín? Bueno, nosotros sabemos por qué. Todos ellos adoran tener un trabajo súper flexible, ganar mucho dinero y ser su propio jefe, justamente las razones por las que ya se han sumado a la red de Foodora" (Ivanova et al., 2018: 5).

${ }^{16}$ No obstante, cabe destacar que, pese a la existencia de estas nuevas formas de control - puede consultarse una descripción detallada de la relación dominación-algoritmos en Ivanova et al. (2018) y Woodcock (2020)-, también han aparecido movimientos de resistencia y solidaridad entre los propios trabajadores. Tassinari y Maccarrone (2020) han analizado las formas de acción colectiva emergentes entre trabajadores de la gig economy - y también su relación con los sindicatos- a partir del análisis de caso de las huelgas de Deliveroo-Londres y Foodora-Turín en el segundo semestre de 2016. Por otra parte, Cant (2020) también ha estudiado la "organización invisible" de repartidores de Deliveroo en Brighton a partir de masivas redes comunicativas físicas y digitales construidas por los propios riders. 
¿Cuáles son las causas que llevan a una persona a asumir tal nivel de servidumbre? En el caso concreto de Rappi:

[Esta app-empresa] se alimenta, por un lado, de dos debilidades muy concretas y complementarias: la necesidad del inmigrante y la desesperación del desempleado. Por el otro, de la fetichización de la inmediatez. No importa cuán lejos se encuentre el restaurante. Toco la pantalla y lo obtengo. Rappi, entonces, rompe con el concepto de delivery tradicional que implicaba cercanía y hasta conocimiento de los repartidores, que muchas veces se peleaban por llevarle la comida al cliente con fama de generoso (Gullo, 2018).

En realidad, no hay otra cosa que articulación hegemónica de las demandas, los deseos y las aspiraciones concretas de la gente, a la vez que el establecimiento de un conjunto de límites dentro de los cuales cada uno puede ser "empresario de sí". El resultado final: precariedad, dominación biopolítica y batalla por el tiempo. Ya lo aventura Judith Butler cuando afirma que "la precariedad se ha convertido en un régimen, en un modo hegemónico de ser gobernados y de gobernarnos a nosotros mismos" (Butler, 2016: 13). Ante esta situación, ¿̇ué salidas quedan?

\section{A modo de conclusión. Y una alternativa}

A lo largo de estas páginas, se ha llevado a cabo el intento de analizar los cambios sucedidos en la gubernamentalidad neoliberal y la forma en la que se han articulado un conjunto de relaciones sociales fluidas caracterizadas por la falta de orden estructural. Consecuencia de ello, han aparecido nuevos vínculos con el mercado laboral, como es el caso de la economía colaborativa, que implican una vulnerabilidad y precariedad que no estaban presentes en el anterior modelo fordista. En este sentido, creemos haber puesto de manifiesto que este tipo de economía on demand atesora una lógica propia y que, por tanto, requiere de unas propuestas de superación diferentes a las ensayadas hasta entonces por el grueso del movimiento obrero. Así pues, llegados a este punto, es menester sintetizar los principales hallazgos del artículo y presentar una alternativa práctica que permitiría subvertir los principios que fundamentan el auge de estas apps-empresa.

En primer lugar, se ha tratado de poner en diálogo la tradición gramsciana de la hegemonía con los aportes foucaultianos del poder con el fin de caracterizar la lógica que rige el neoliberalismo. Como se ha visto, el análisis de la racionalidad política neoliberal debe tener en cuenta dos dimensiones clave. Por una parte, la dimensión hegemónica, ya que el ciclo actual del capitalismo es capaz de universalizar lo particular a partir de la articulación subordinada de las aspiraciones populares: subsume en lógicas mercantiles multitud de relaciones que anteriormente se encontraban fuera de ellas, mientras que, a la vez, es capaz de reconocer y satisfacer 
demandas democráticas de diferentes sectores en una suerte de revolución pasiva constante. Por otra parte, la dimensión biopolítica, a saber, la nueva forma que tiene el neoliberalismo de organizar los regímenes de verdad -más centrada en el "dejar hacer" y el cálculo poblacional-económico que en la disciplina de los cuerpos- y que produce subjetividades y modos en los que dichos sujetos se relacionan con su realidad material, también afectada por la nueva configuración de la gubernamentalidad liberal.

En segundo lugar, a partir de la reconceptualización realizada por Harvey, se ha demostrado que, si la acumulación por desposesión es el modo de actuación distintivo del neoliberalismo, la carencia de orden estructural en las relaciones sociales es su resultado definitivo. Ante este desorden total, ha surgido toda una economía de plataformas que, a la vez que explota un deseo anticapitalista de rechazo al trabajo, precariza a sus empleados a través de nuevas realidades, como la figura del "falso autónomo", la función objetiva de los algoritmos, la falta de regulación laboral o la cuasi imposible posibilidad de organización sindical. Todo ello aderezado con un discurso cuya centralidad ocupa una noción muy concreta de libertad: aquella que promete un trabajo libre, sin jefes, sin horarios y con ganancias inmediatas.

De hecho, cuando se habla del concepto de libertad, fundamento filosófico básico de las sociedades modernas, uno suele quedarse atrapado en aquella distinción que popularizó Isaiah Berlin (1988) entre libertad positiva y libertad negativa, que no era más que una reformulación terminológica de la distinción que ya realizó Benjamin Constant entre libertad de los antiguos y libertad de los modernos. En última instancia, lo que Berlin buscaba al hacer esto era justificar la (liberal) libertad negativa, entendida como no interferencia, en oposición a la (democrática) libertad positiva, entendida como autodominio del ser humano. Para escapar de esta aporía, aquí se prefiere caracterizar la libertad al estilo de la olvidada libertad republicana, es decir, como no dominación o no dependencia de un tercero (Pettit, 1999: 40-46). Producto de una larguísima tradición política e intelectual que se remonta a la Antigua Grecia, la libertad republicana reside en garantizar la existencia material de toda la población (Domènech y Raventós, 2007), lo cual solamente puede hacerse efectivo mediante un derecho social de existencia públicamente garantizado o de una renta material asignada de forma incondicional a todos los ciudadanos por el simple hecho de serlo (Domènech, 2013: 20). Hoy en día, ese derecho social de existencia es la Renta Básica Universal e Incondicional.

$\mathrm{Al}$ recibir una asignación monetaria incondicional - es decir, no condicionada a ningún tipo de nivel de renta, género, disfunción, etc.- y universal -o sea, que la reciben todas las personas por el simple hecho de ser ciudadanas de un Estado- se rompe con la denominada "trampa de la pobreza" y con todos los prejuicios que suelen ir asociados a las rentas mínimas de inserción, esto es, a los subsidios condicionados. Sin embargo, más allá de eso, lo que nos interesa de la Renta Básica es la 
capacidad que daría a aquellos que la recibiesen de rechazar trabajos que, como los de la economía colaborativa, condenan a la precariedad. Al fin y al cabo, se trata de garantizar la no dominación de los ciudadanos, de ofrecerles tiempo libre no subsumido a lógicas mercantiles. Una no dominación que debe entenderse como la forma de poder escapar - al menos parcialmente- a la producción de subjetividades que encierra la racionalidad neoliberal: aquella que obliga a aceptar un conjunto de trabajos precarios que, al subordinar completamente el tiempo de vida al tiempo de trabajo, impiden el ejercicio de la libertad republicana, a saber, la constitución de sujetos libres e iguales.

\section{Bibliografía}

Agamben, G. (1998). Homo Sacer I: el poder soberano y la nuda vida. Valencia: Pre-Textos.

Agamben, G. (2017). Creazione e anarchia: l'opera nell'età della religione capitalista. Vicenza: Neri Pozza.

Agüero, J. O. (2010). Michel Foucault y la gubernamentalidad financiera: reflexiones sobre la crisis financiera internacional. Revista Científica Visión de Futuro, 14 (2), en https://revistacientifica.fce.unam.edu.ar/index.php/visiondefuturo/article/view/708.

Alemán, J. (2016). Capitalismo y hegemonía: una distinción clave. La Circular, 5, $72-75$.

Althusser, L. (2003). Ideología y aparatos ideológicos de Estado. Freud y Lacan. Buenos Aires: Nueva Visión.

Anderson, P. (1981). Las antinomias de Antonio Gramsci: Estado y revolución en Occidente. Barcelona: Fontamara.

Anderson, P. (2018). La palabra H: peripecias de la hegemonía. Madrid: Akal.

Barrett, M. (1991). The Politics of Truth: From Marx to Foucault. Stanford: Stanford University Press.

Bedoya, M. y A. Castrillón (2017). Neoliberalismo como forma de subjetivación dominante. Dorsal. Revista de Estudios Foucaultianos, 3, 31-56.

Berlin, I. (1988). Cuatro ensayos sobre la libertad. Madrid: Alianza.

Berrío, A. (2010). La exclusión-inclusiva de la nuda vida en el modelo biopolítico de Giorgio Agamben: algunas reflexiones acerca de los puntos de encuentro entre democracia y totalitarismo. Estudios Políticos, 36, 11-38.

Bidet, J. (2014). Foucault avec Marx. París: La fabrique.

Brown, W. (2016). El pueblo sin atributos: la secreta revolución del neoliberalismo. Barcelona: Malpaso.

Butler, J. (2016). Prefacio. En I. Lorey. Estado de inseguridad: gobernar la precariedad. Madrid: Traficantes de Sueños. 
Cadahia, L. (2018). Las fisuras del ethos neoliberal. Reporte Sexto Piso, 44, 11-12.

Campione, D. (2007). Para leer a Gramsci. Buenos Aires: Ediciones del Centro Cultural de la Cooperación Floreal Gorini.

Cant, C. (2020). The warehouse without walls: A workers' inquiry at Deliveroo. ephemera: theory \& politics in organization, 20 (4), 131-161.

Castro-Gómez, S. (2005). Foucault, lector de Marx. Universitas Humanística, 59, 107-117.

Chen, J. Y. y P. Sun (2020). Temporal arbitrage, fragmented rush, and opportunistic behaviors: The labor politics of time in the platform economy. New Media \& Society, 22 (9), 1561-1579.

Deleuze, G. (1990). Postdata sobre las sociedades de control. En C. Ferrer (comp.). (2005). El lenguaje libertario: antología del pensamiento anarquista contemporáneo. La Plata: Terramar.

Domènech, A. (2013). La metáfora de la fraternidad republicano-democrática revolucionaria y su legado al socialismo contemporáneo. Revista de Estudios Sociales, 46, 14-23.

Domènech, A. y D. Raventós (2007). Property and Republican Freedom: An Institutional Approach to Basic Income. Basic Income Studies, 2 (2), 1-8.

Drahokoupil, J. y A. Piasna (2019). Work in the Platform Economy: Deliveroo Riders in Belgium and the Smart Arrangement. ETUI Research Paper - Working Paper, en https://dx.doi.org/10.2139/ssrn.3316133.

Errejón, Í. (2018). En caso de duda: volver a Gramsci. En M. Larrauri y D. Sánchez. Contra el elitismo: Gramsci: manual de uso. Barcelona: Ariel.

Estévez Araújo, J. A. (2021). Las transformaciones económicas de la globalización neoliberal. En J. A. Estévez Araújo (ed.). El derecho ya no es lo que era: las transformaciones jurídicas en la globalización neoliberal. Madrid: Trotta.

Ferguson, S. (2020). Mujeres y Trabajo: feminismo, trabajo y reproducción social. Barcelona: Sylone/Viento Sur.

Foucault, M. (2003). Hay que defender la sociedad: curso del Collège de France (1975-1976). Madrid: Akal.

Foucault, M. (2005). Historia de la sexualidad 1: la voluntad de saber. Ciudad de México: Siglo XXI.

Foucault, M. (2008). Seguridad, territorio, población: curso del Collège de France (1977-1978). Madrid: Akal.

Foucault, M. (2009). Nacimiento de la biopolítica: curso del Collège de France (1978-1979). Madrid: Akal.

Foucault, M. (2018). La sociedad punitiva: curso del Collège de France (1972-1973). Madrid: Akal.

Gramsci, A. (2013). Antología. Buenos Aires: Siglo XXI. 
Gullo, E. (2018). Capitalismo con tracción a sangre. Revista Anfibia, en http://revistaanfibia.com/cronica/capitalismo-traccion-sangre/.

Hall, S. (2017). Estudios culturales 1983: una historia teorética. Buenos Aires: Paidós.

Han, B.-C. (2014). En el enjambre. Barcelona: Herder.

Harvey, D. (2004). El nuevo imperialismo. Madrid: Akal.

Harvey, D. (2008). El neoliberalismo como destrucción creativa. Apuntes del CENES, 27 (45), 10-34.

Ivanova, M., J. Bronowicka, E. Kocher y A. Degner (2018). Foodora and Deliveroo: The App as a Boss? Control and autonomy in app-based management - the case of food delivery riders. Working Paper Forschungsförderung, 107, en http://hdl.handle.net/10419/216032.

Kreps, D. (2015). Introduction. En D. Kreps (ed.). Gramsci and Foucault: A Reassessment. Farnham: Ashgate.

Laclau, E. (2005). La razón populista. Buenos Aires: Fondo de Cultura Económica.

Laclau, E. (2007). Emancipation(s). Londres: Verso.

Laval, C., L. Paltrinieri y F. Taylan (dirs.). (2015). Marx \& Foucault: lectures, usages, confrontations. París: La Découverte.

Legrand, S. (2004). Le marxisme oublié de Foucault. Actuel Marx, 36 (2), 27-43.

Lordon, F. (2015). Capitalismo, deseo y servidumbre: Marx y Spinoza. Buenos Aires: Tinta Limón.

Maltese, P. (2017). Gramsci e Foucault, Foucault e Gramsci. Materialismo Storico, 2 (1), 164-202.

Marcuse, H. (2010). Eros y civilización: una investigación filosófica acerca de Freud. Barcelona: Ariel.

Marx, K. y F. Engels (1975). Obras escogidas de Marx y Engels, II vols. Madrid: Fundamentos.

Moruno, J. (2015). La fábrica del emprendedor: trabajo y política en la empresamundo. Madrid: Akal.

Moruno, J. (2018). No tengo tiempo: geografias de la precariedad. Madrid: Akal.

Nosetto, L. (2013). Michel Foucault y la política. San Martín: UNSAM EDITA.

Olssen, M. (1999). Michel Foucault: Materialism and Education. Londres: Bergin \& Garvey.

Pettit, P. (1999). Republicanismo: una teoría sobre la libertad y el gobierno. Barcelona: Paidós.

Sardinha, D. (2018). Marx y Foucault. El nominalismo de la relación como principio anti-metafísico. En J. L. Villacañas y R. Castro Orellana (eds.). Foucault y la historia de la filosofía. Madrid: Dado.

Smith, A. (1994). La riqueza de las naciones. Madrid: Alianza. 
Standing, G. (2013). El precariado: una nueva clase social. Barcelona: Pasado y Presente.

Tassinari, A. y V. Maccarrone (2020). Riders on the Storm: Workplace Solidarity among Gig Economy Couriers in Italy and the UK. Work, Employment and Society, 34 (1), 35-54.

Thompson, E. P. (1984). Tradición, revuelta y consciencia de clase: estudios sobre la crisis de la sociedad preindustrial. Barcelona: Crítica.

Tsing, A. L. (2021). La seta del fin del mundo: sobre la posibilidad de vida en las ruinas capitalistas. Madrid: Capitán Swing.

Woodcock, J. (2020). The algorithmic panopticon at Deliveroo: Measurement, precarity, and the illusion of control. ephemera: theory \& politics in organization, 20 (3), 67-95. 